\title{
Uterine artery rupture during labour
}

\author{
M. Thirukumar \\ Faculty of Health Care Science, Eastern University, Sri Lanka
}

\author{
Article information \\ Total number of \\ Words 687 \\ Authors have no conflicts of interest to \\ declare
}

Keywords: uterine artery rupture, labour

Date of submission: 02.12.2018

Date of acceptance: 10.10 .2019

\author{
Author responsible for correspondence: \\ Dr. M. Thirukumar \\ Department of Clinical Science \\ Faculty of Health Care Science, Eastern \\ University, Sri Lanka \\ dr.thiru10@yahoo.com \\ https://orcid.org/0000-0001-8499-7175 \\ DOI: http://doi.org/10.4038/cjms.v56i1.4947
}

\begin{abstract}
Spontaneous rupture of uterine vessels, particularly intra-partum, is a rare cause of maternal death during pregnancy. Awareness about this condition, may help to avoid delayed diagnosis and facilitate early resuscitation. This case is reported to highlight the importance of considering common as well as rarer life-threatening causes of obstetric shock in the differential diagnosis.
\end{abstract}

\section{Introduction}

Spontaneous rupture of uterine vessels is a rare, life-threatening condition that causes high maternal and perinatal mortality[1]. Most reported cases have occurred during antenatal and postnatal period but is less reported during labour[2]. Most (75\%) of the ruptures were within the broad ligament. They present with sudden abdominal pain, hemodynamic collapse with decrease in hemoglobin and hematocrit levels[3].

The aetiology of spontaneous rupture of uteroovarian vessels during pregnancy remains poorly understood. However, several aetiologic hypotheses have been postulated, based on the previously reported cases: arteriovenous malformation, uterine artery aneurysm[4], endometriosis[5], increase in venous pressure, free anastomosis of uterine and ovarian vessels within the broad ligament and absence of valves in the ovarian veins. Further, estrogen induced intimal changes, the tortuous path of uterine and ovarian veins and distention with intraluminal pressure may predispose them to bleed spontaneously[6-9].

Dextro-rotation of uterus and left occipital position of the fetus could be the possible predispositions for the more frequent left sided involvement[10].

\section{Case Report}

A 35-year-old mother in her fifth pregnancy with four previous vaginal deliveries was admitted for confinement in the 38th week of gestation. She had both pre-existing diabetes mellitus and preexisting hypertension and was on metformin, insulin, nifedipine and low dose aspirin from her 10 weeks of gestational age. Her blood pressure and diabetes were well controlled. 
The uterine cervix was primed with Foley's catheter followed by $1 \mathrm{mg}$ of vaginal prostaglandin. Ten hours after vaginal prostaglandin, she developed uterine contractions. Two hours after admission to labour room, the oxytocin infusion was commenced to augment the poor progress of labour. Two hours later her blood pressure increased to $178 / 84 \mathrm{mmHg}$ and it was controlled with a single dose of intravenous hydralazine. The labour progressed well thereafter.

She delivered a four kg baby by forceps delivery, 5 hours and 20 minutes after admission to the labour room. She developed mild dyspnea and become pale 10 minutes postpartum. Her pulse rate was found to be 110 beats/minutes with elevated blood pressure of $170 / 110 \mathrm{mmHg}$. Lungs showed equal air entry with no crepitations. The uterus was well contracted and below the umbilical level. The blood pressure was controlled with a second dose of intravenous hydralazine.

Thereafter, her condition deteriorated quickly. She became more dyspneic and paler than previously. Her pulse rate increased to 140 beats per minuteand blood pressure dropped to 133/97 $\mathrm{mmHg}$. Lungs still had no crepitations and uterus remained well contracted. No excessive bleeding per vaginum was noted. The drop-in blood pressure with tachycardia was attributed to the hydralazine administration or a myocardial infarction or amniotic fluid embolism. The hypovolemia due to bleeding was not suspected. Patient was transferred to the intensive care (ICU) unit within 10 minutes where she developed a cardiac arrest. Cardio pulmonary resuscitation (CPR) failed to bring her back to life.

Postmortem report revealed right side uterine artery rupture, without uterine wall rupture, into the broad ligament with about $900 \mathrm{ml}$ of blood clot. The rupture did not open into the peritoneal cavity.

\section{Discussion}

Spontaneous rupture of uterine vessels has been reported during pregnancy and less commonly in postpartum period. This case occurred during intrapartum. The clinical manifestation is mostly sudden abdominal pain with hemodynamic collapse along with a decrease in hemoglobin and hematocrit levels[3].
The diagnosis of ruptured uterine vessels has rarely been made preoperatively, especially in cases detected after delivery[10]. This case was diagnosed post-mortem. The volume of blood clot was only $900 \mathrm{ml}$. As $900 \mathrm{ml}$ of blood loss would not have been lethal, other contributory mechanisms such as neurogenic shock due to stretching of broad-ligament stimulating parasympathetic nerves of pelvis resulting in hypotension is postulated in this case.

The case under reference developed shock soon after forceps delivery and died due to unsuspected uterine artery rupture. When her condition deteriorated rapidly, the tachycardia with hypotension was falsely attributed to the treatment of hypertension with intravenous hydralazine. The possibility of hypovolemia was not considered and overlooked resulting in the death.

This case is being reported to emphasize the need for careful post-delivery monitoring not only for revealed postpartum hemorrhage, but also for other rarer life-threatening causes of obstetric shock.

\section{References}

1. Ziereisen V, Bellens B, Gerard C,et al. Spontaneous rupture of utero-ovarian vessels in postpartal period: a case report and review of literature. J Gynecol Obstet Biol Reprod (Paris). 2003; 32:51-4.

2. Becker R, Kowalsky BL, Hatzmann W. Rupture of the uterine artery after spontaneous delivery with unusual course in childbed.Z Geburtshilfe Neonatol.2002;206:107-13. https://doi.org/10.1055/s-200232643.PMid:12098827.

3. Swaegers MCR, Hauspy JJP, Buytaert PMHG, et al. Spontaneous rupture of the uterine artery in pregnancy. EurJ Obstet Gynecol Repro Biol. 1997; 75:145-6. https://doi.org/10.1016/S03012115(97)00121-8

4. Liu CM, Hsu JJ, Hsieh TT, et al Postpartum hemorrhages of the uterine artery rupture. Acta Obstet Gynecol Scand 1998; 77(6):695-7. PMid: 9688252

5. Lajtman E, Mlyncek M, Uharcek P, et al. Spontaneous rupture of uterine vessels during pregnancy in a patient with previous endometriosis. Ceska Gynekol. 2011;76(2):161-3. PMid:21650003

6. Cole $\mathrm{M}$, Elton $\mathrm{C}$, Bosio $\mathrm{P}$, et al. Spontaneous rupture of utero-ovarian vessels in labour-a rare case of obstetric 
hemoperitoneum.j obsete gynaecol 2005;25(3):301-3.

7. Gard M, Hudeyin S, Aquilina J Silent, massive hemoperitoneum during labour secondary to a spontaneous rupture of a utero-ovarian vessel. J Obstet Gynaecol 2003; 23(2):208-9.

8. Moreira A, Reynolds A, Baptista P, et al. Case report: Intra-partum útero-ovarian vessels rupture Arch Gynecol Obstet 2009;279:583-5.

9. Ginsberg KA, Valdes C, Schnider G. Spontaneous utero-ovarian vessel rapture during pregnancy: three case reports and a review of the literature. Obstet Gynecol. 1987;69:474-6.

10. Duhan Nirmala et al. Spontaneous Uterine Artery Rupture at Delivery. The Journal of Obstetrics and Gynecology of India (January-February 2013) 63(1):72-73 .https://doi.org/10.1007/s13224-012-0142$\mathrm{z}$ 